\title{
Extended Study of Undergraduate Students' Usage of Mobile Application for Individual Differentiation Learning Support of Lecture-based General Education Subjects
}

https://doi.org/10.3991/ijim.v13i09.10558

Sumitra Nuanmeesri

Suan Sunandha Rajabhat University, Bangkok, Thailand

sumitra.nuessru.ac.th

\begin{abstract}
This is an investigation in the development and assessment of a mobile device application that was developed for differentiated (individualized) learning in support of lecture-based general education subjects. As a substantial number of students were experiencing difficulty in successfully completing university courses, a mobile device application was developed as a learning aid that the students could utilize to assist them in their studies. The mobile application contains uploaded course content from each course. This was used to create a summary of the lecture content from each course, in the form of infographics and linked 'PDF files' or soft copies of lecture materials. The application includes exercises that students can complete, which contribute to self-created content based on their understanding, skills, and interests. With use of the mobile application, $100 \%$ of the students successfully completed these courses. Moreover, the level of satisfaction in education among students was high with an average of 4.75 . The standard deviation of 0.43 indicated that, concerning contemporary education, and the active learning atmosphere, effective learning can be achieved with the development of electronic mobile device learning applications. This form of learning provides opportunities to students to use their creativity and preferred methods in problem solving, whilst demonstrating their understanding about lesson content.
\end{abstract}

Keywords-Individual differentiation, mobile application, learning support, education

\section{Introduction}

It is universally accepted that current education should accommodate individual differences and learning preferences by eliciting active learning within a self-directed learning approach [1]. Student-centered learning is enabled by focusing on or applying personal interests, capabilities, and talents in teaching and learning. Educational institutions should be proactive in understanding that students have a variety of tools that they may use for studying. Students now have access to a wide amount of 
knowledge on the internet, which is not limited by place and time. According to the lecture-based educational problems, reviewing a lesson by answering the multiple choice and short answer exercises usually limits a students' ability to demonstrate their understanding about the course content, especially where courses that have more than 100 students studying in the one classroom. This appears to be common practice for general education courses, which must be taken by students from every department [2]. Moreover, some students may not be interested in these classes [3]. As students may not pay attention in class, and the class environment may not attractive enough to encourage study, students are often distracted into using their smartphones in class. This often leads to exam failure or course cancellation among many. Therefore, modern education should incorporate technology and innovation.

Presently, smartphones play a significant role in every person's daily activities. People around the globe have adopted this advanced technology as one of the most critical facilities required in their everyday life. A smartphone is a pocket-sized computer in which its popularity can promote learning. There has been widespread use of mobile technologies among the young generations [4]. Thus, it is suggested that educational institutions with limited information and communication technology (ICT) resources to take advantage of this technology. Sharples (2003) notes that instead of considering them as disruptive devices, educators may better attempt to make use of their potential and explore possible learning practice benefits. Mobile technologies give the educational system opportunities to make a fundamental change by moving it away from the traditional use of a computer in a laboratory to having a permanent place in the classroom [5].

Mobile learning, (also known as 'M-Learning'), is an innovation in the educational environment which is a recent and independent component of E-Learning [6][7][8]. Crompton (2013) states M-Learning is a kind of learning towards diverse contexts, through social and content-based interactions, and utilizing personal electronic devices [9] [10] [11]. Traxler (2007) apparently advocates M-Learning as a type of cognitive stimulation in multidisciplinary educational fields [12]. Because of the increasing recognition of M-Learning, there have been a few of studies on its advantages in relation to learning [13] [14] [15] [16] [17]. Simultaneously, Cochrane and Bateman (2010), and Dyson et al. (2009), suggested that the strengths of M-Learning including its mobility and flexibility, facilitating an extended learning environment [15] [16]. M-Learning is an extraordinary style of learning since it gives students the increased accessibility to course materials, instructions, and other course-related applications, anytime and anywhere [18]. M-Learning is a learning approach in which there is the intersection between E-Learning and mobile computing [19] [20], integrating miscellaneous software and hardware in multimedia applications [21], which enhances learning through numerous wireless devices, by applying wireless internet (Wi-Fi) technology [22] [23], and broadband services, without location or time constraints [24] [25]. M-Learning refers to learning various contexts, social relationships, and subject content, which uses personal electronic devices. Contexts here refer to engaging in formal learning, self-learning, and spontaneous learning [26]. Berge and Muilenburg (2013) note that self-learning and spontaneous learning are embedded in both informal and non-formal curricula [13]. In the studies conducted by O'Donoghue 
(2010) and Traxler (2007), there was an emphasis on the characteristics of MLearning, reducingtime and space limitations, while providing a universal learning environment [12] [27].

Students in the modern era have been coined by Prensky (2001) as 'Digital Natives', who are greatly mobilized by present-day technological advancements [28]. This generation is generally equipped with competence and knowledge in employing hi-tech devices and intermittently using the internet to acquire important information to aid them in their education. Their favorite tools are high-mobility and informative internet content, which are accessible with mobile devices. Bomhold (2013) suggests in his study on mobile apps in higher education that a majority of university students (76\%) used smartphone apps for academic purposes. In his research, there was a comparison of application usage between different groups of students (classified by their areas of study) [29]. Kim et al. (2013) also analyzed how students at a Korean university in education and engineering, regularly used different smartphone applica-tions for learning. The research results suggested that those students who frequently used smartphones tended to spend more time on learning applications; however, they would install fewer learning applications on their phones when compared with others. With regard to student motivation in the use of mobile learning applications [30], Bomhold (2013) proposed that the process of data acquisition must be considerably convenient for today's digital natives; this is because they expect that the information must be accessible ubiquitously [29]. Even with the rise in mobile learning, there are only a few studies that paid attention to student knowledge acquisition. Since mobile applications and the utilization of mobile technology, had become more acknowledged, it was significant for the researchers and practitioners in the field of mobile learning to study the potential factors influencing the learning outcomes [31]. According to the data from the pre-tests and post-tests on inquiry approach-based, mobile learning, it was found that students who studied using inquiry approach-based, mobile learning, gained achieved higher scores, and suffered less cognitive load, when compared to those who studied under traditional instruction [32].

Today's students often use smartphones to the point of what can be called 'smartphone addiction'. It is common to see students playing with their smartphones while an instructor is teaching in front of the class. If there is an application on smartphones to support education, it may make student learning more attractive, and thus gaining and maintaining their attention. Nowadays, smartphone technology offers a variety of features, including a camera with photos and video facilities that allow retouching and editing applications. With such ability, this allows students to find and answer questions while self-learning. Students are unique and have their own different ideas and approaches to finding answers. For example, if the answer to a question is 'an ant', some students might answer by typing the word 'ant', while some might search for 'ant' on the internet and attach the source link, take a photo, or video of ants, draw a picture of ants, or even edit a picture of ants with their smartphone application. This shows that students can answer a question in several ways; which may encourage learning and allow students more freedom in completing tasks. Hence, students will not be limited to select a fixed choice(s) or narrate their ideas by written texts. 
This research aims to promote education among students by allowing access to modern and appropriated infographics. The content summary for each lesson is linked with PDF files or soft copies of the lecture texts. For the convenience of students, lesson content and exercises were implemented for students to review, in the form of file attachments. Students can create answers by taking a photo or video as well as using the related information from different websites to answer the questions in the exercises on their smartphones. Accordingly, students will not be constrained in completing exercises. This ability allows students to develop original ideas, and provides a platform for them to demonstrate their interests and abilities, while contributing to the development of the active learning environment.

\section{$2 \quad$ Methodology}

The research methods for studying the development of the extended study of undergraduate students' usage of mobile application for individual differentiation Learning support of lecture-based general education subjects, include the following steps:

\subsection{Collection data}

The selection of the content and exercises for each lesson in the textbook of each general education subject there being eight lecture subjects that second year and third year students from every department were required to study, according to their course curriculum; the eight subjects consisted of two subjects from the language modules, two subjects from the humanities and social science modules, two subjects from the science and mathematics modules, and two subjects from the information technology modules. There were eight professors who had in-depth knowledge in these eight subject fields and contributed to this research by providing lesson content for the construction of the mobile application.

\subsection{Design of the mobile application}

Design of the mobile application was divided into three parts: first, the development of the content summary of each chapter using infographics; second, the conversion of the content into PDF files (which are associated with the infographics from the previous step); and third, the exercises for each chapter were developed. The exercises had been designed to include the fill-in-the-blanks, matching, file attachments, and links to online sources, to ensure that each learner can understand the lesson in each chapter by using the infographics. Also, each learner could click to see the full-text contents in the PDF files. Once the lesson was completed, the learner can review the content by doing the exercises which consist of the fill-in-the-blanks, matching, attaching files e.g. picture, sound, movie, and inserting links from the internet. This allowed each learner to create their own learning content by answering the questions according to his/her interests using the file attachment option. 


\subsection{Development of the mobile application}

The mobile application, was developed on the Android operating system, using 'Android Studio' software. The learner could download and install the mobile application onto their electronic device. Once operational, the application provided the option to access the content of each course, displayed in the form of infographics. The content of each course was presented in the form of PDF files like E-books, game-like exercises, and the official websites of each course.

Development of the mobile application using the infographics to summarize the content of each chapter, allows the learner to review the content of each chapter. Understanding of the content was aided by the use of illustrations. As shown in Figure 1, the learner can easily comprehend the content structure of each chapter by observing the pictures one-by-one. The learner also can access the full text of each content by opening the PDF files and E-books as shown in Figure 2. Figure 3 illustrates an example of what a learner can review, in regard to content and game-like exercises which compose of fill-in-the-blanks, matching, file attachments, and link insertion of online sources, which allows the learner to apply the usage of smartphones for learning and completing the exercise.

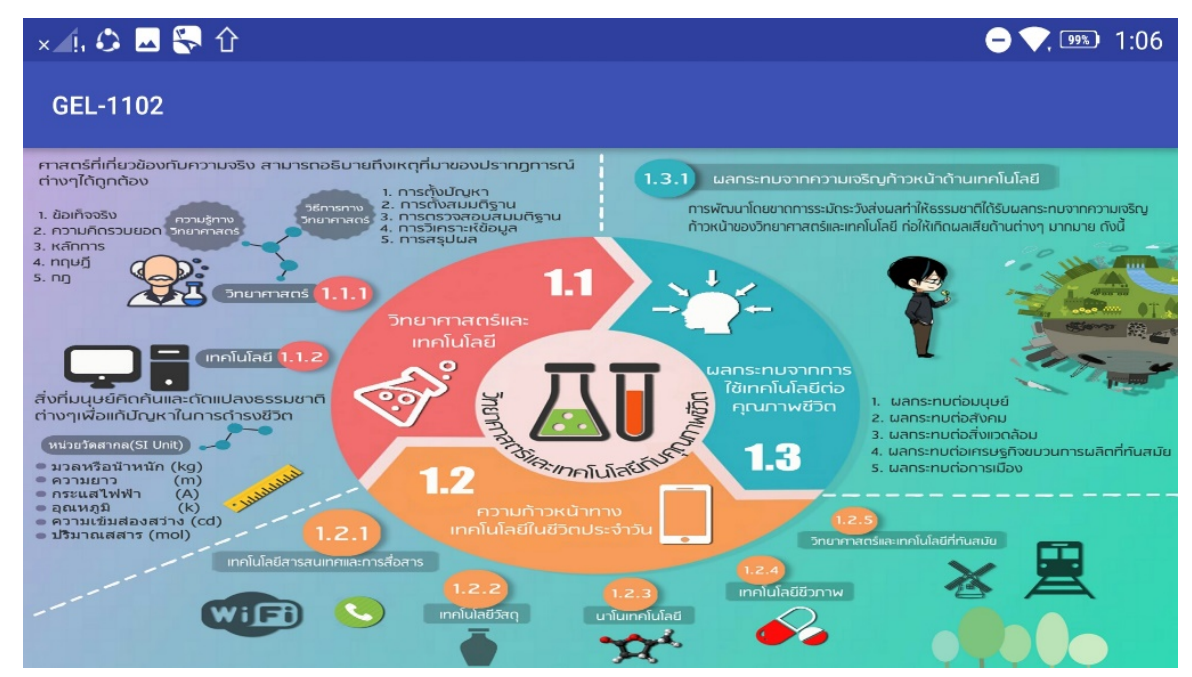

Fig. 1. The display of the summary content using infographics on the mobile application 


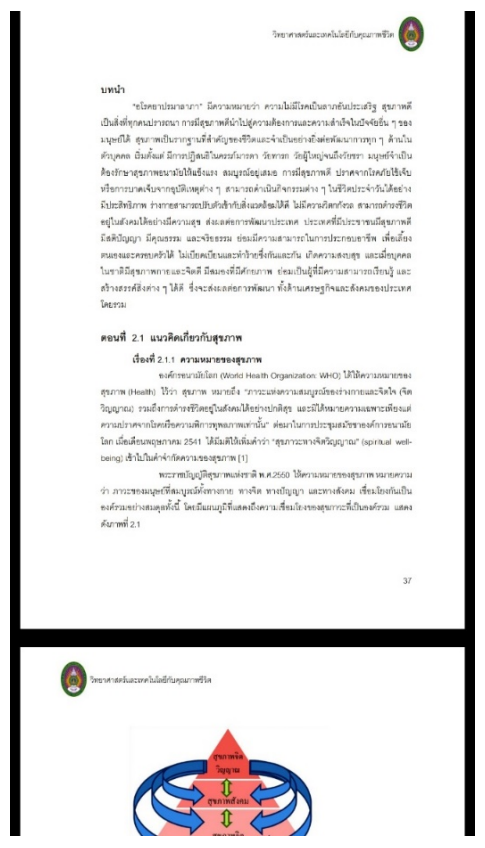

Fig. 2. The display of the content in PDF form on the mobile application

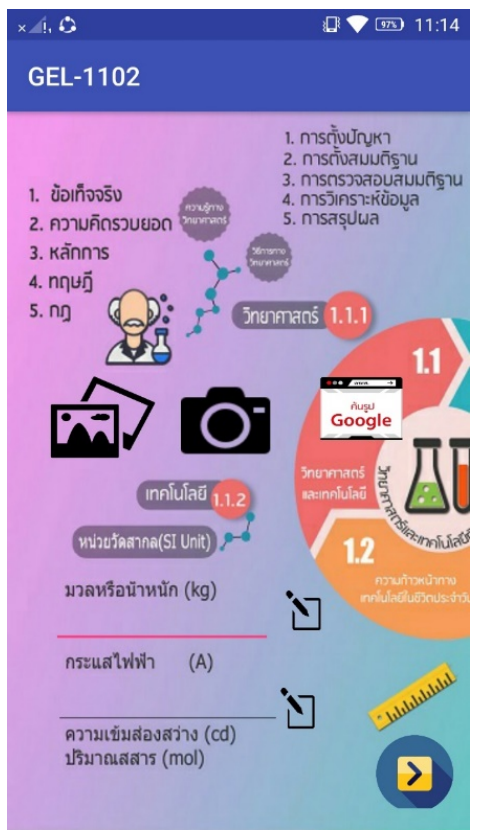

Fig. 3. The display of the exercises on the mobile application 


\subsection{Evaluation of the mobile application}

The mobile application was tested by 117 voluntary Year 2 and Year 3 undergraduate students from the Information and Communication Technology Department from the announcement of the research team on social media. Students used the mobile application through the use of an assigned student code, so researchers had no information with regard to student identification and their performance. This was the basis upon which ethics approval was obtained for the study. Subjects were requested to install and use the mobile application during the 14 weeks course. The professors, who were responsible for each of the eight courses, were also the examiners in assessing student responses to each exercise.

collected information regarding student perception in the usefulness of the mobile application, as well as the application's contribution to learning.

Questions in the questionnaire was evaluated by five experts who are specialized in the field of information technology and education. The evaluation used the Index of item objective congruence (IOC) [33] to give scores. If the criteria determined by the IOC value of each indicator was higher than 0.5 (the highest IOC value is 1), it means the questionnaire met the objective, possessed content suitable for education purposes, and therefore, the questionnaire worked effectively. The IOC value of each indicator was 0.8 , indicating that the questionnaire met the objective and is suitable for using in education. The experts were able to provide a rating by using the assessment criteria as in Table 1.

Table 1. Rating criteria for content consistency and application workability

\begin{tabular}{|c|l|}
\hline Rating criteria & \multicolumn{1}{c|}{ Meaning } \\
\hline 1 & There is content consistency and that the application works. \\
\hline 0 & $\begin{array}{l}\text { Uncertainty in content consistency and application } \\
\text { workability. }\end{array}$ \\
\hline-1 & No content consistency nor it cannot work. \\
\hline
\end{tabular}

Subsequently, taking the information from the experts and finding the IOC value by using the formula as shown in the equation:

$$
\mathrm{IOC}=\frac{\sum \mathrm{R}}{\mathrm{N}}
$$

$\sum \mathrm{R}$ is the sum of the scores that the experts rated.

$\mathrm{R} \quad$ is the score that the experts rated.

$\mathrm{N} \quad$ is the number of the experts.

From the IOC, the evaluation used IOC, the questionnaire of the evaluation of mobile application consisted of the following:

- Usability consists of the following questions: that is, perceived usefulness [34], and perceived ease of use [35] such as ease of use, the occurrence if there is of system failure when the user access, the evaluation score is low in this topic. 
- Learning experience consists of the following questions: learning experience presence [34], motivation [36], cognitive benefits [37], perceived learning effectiveness [34], and satisfaction [38].

In evaluation of mobile application use the online questionnaire. The data obtained from the questionnaire evaluation was analyzed by the statistics used in this research to determine are the arithmetic mean, standard deviation and percentage.

\section{Results}

Of the 117 sophomores and junior undergraduate students participating in this study, a comparison was performed on the students who failed the course (receiving a ' $F$ ' result), and the students who withdrew from the course (that received a ' $W$ ' result) in 2017 and 2018. With regard to the study in 2017, the mobile application was not developed, as such, students had to attend class and make use of hard-copy textbooks, with the completion of lesson exercises on dedicated websites. According to the 2017 class results, 28 students (23.93\%) obtained a ' $\mathrm{F}$ ' and 31 students (26.49\%) got a 'W' result. In comparison with 2018, with implementation of the mobile application, there were no students who failed and only 10 students $(8.55 \%)$ that withdrew from the program. As shown in Figure 4.

\section{The percentage of the learners who got grade}

$F$ and $W$

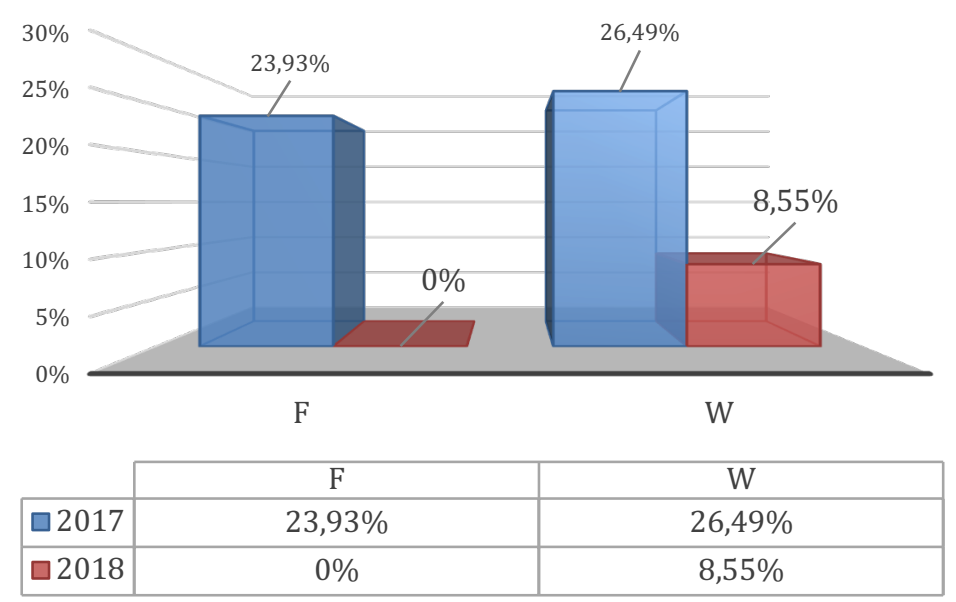

Fig. 4. Comparison of the percentage of learners in the 2017 and 2018 programs who Failed (F) or Withdrew from the program (W)

The evaluation indicators for the developed mobile application was assessed by 117 students, that were sample test group : 1) usability, perceived usefulness [34], and 
perceived ease of use [35]; and 2) learning experience, learning experience presence [34], motivation [36], cognitive benefits [37], perceived learning effectiveness [34], and satisfaction [38].

The subjects were selected from second- and third-year undergraduate students. The data was analyzed to find the mean value and the standard deviation value according to the scoring criteria of Likert Scale [3] to rate as shown in Table 2.

Table 2. Scoring criteria for evaluating the mobile application

\begin{tabular}{|c|c|l|}
\hline Scale & Range of Weighted Mean & \multicolumn{1}{|c|}{$\begin{array}{c}\text { Level of effective mobile } \\
\text { application for learning }\end{array}$} \\
\hline 5 & $4.5-51.00$ & The highest \\
\hline 4 & $3.4-51.50$ & The high \\
\hline 3 & $2.3-51.50$ & The medium \\
\hline 2 & $1.2-51.50$ & Little \\
\hline 1 & $1.1-00.50$ & The least \\
\hline
\end{tabular}

Usability was determined to have a mean of 4.72 and a standard deviation of 0.45 ; and the users' learning experience was rated with a mean of 4.76 and standard deviation of 0.57 . This indicates that the mobile application is an effective tool for learning at a high level, as shown in Table 3.

Table 3. Evaluation of the mobile application for differentiated learning support in lecturebased education

\begin{tabular}{|l|l|l|l|}
\hline \multicolumn{1}{|c|}{ List of assessment } & Arithmetic Mean & Standard Deviation & $\begin{array}{c}\text { Level of effective } \\
\text { mobile application } \\
\text { for learning }\end{array}$ \\
\hline 1. Usability & & & \\
\hline 1.1 Perceived Usefulness & 4.70 & 0.46 & The highest \\
\hline 1.2 Perceived Ease of Use & 4.74 & 0.44 & The highest \\
\hline Conclusion & 4.72 & 0.45 & The highest \\
\hline 2. Learning Experience & & & \\
\hline 2.1 Learning Experience Presence & 4.68 & 0.47 & The highest \\
\hline 2.2 Motivation & 4.79 & 0.41 & The highest \\
\hline 2.3 Cognitive Benefits & 4.77 & 0.42 & The highest \\
\hline 2.4 Perceived Learning Effectiveness & 4.75 & 0.43 & The highest \\
\hline 2.5 Satisfaction & 4.80 & 0.40 & The highest \\
\hline Conclusion & 4.76 & 0.57 & The highest \\
\hline Conclusion for all aspects & 4.75 & 0.43 & The highest \\
\hline
\end{tabular}

From a comparison of the student groups who accessed the application to complete the exercises, $70 \%$ of the learners completed the exercises by attaching files, $15 \%$ did the exercises by inserting links to online sources, $12 \%$ used matching, and $3 \%$ filled in the blanks as shown in Figure 5. This shows that the learners actively used the application and took advantage of the applications features to complete the exercises. The majority of students answered the questions by using file attachments. Figure 6 
shows the four file types that were attached in completing the exercises. These are listed below:

- Videos containing motion pictures with sounds and/or texts accounted for $45 \%$.

- JPG photos shot by digital cameras or smartphones made up 35\%.

- BMP or PNG edited pictures took up $11 \%$.

- MP3 or WAV audios containing instrumental sounds or music comprised 9\%.

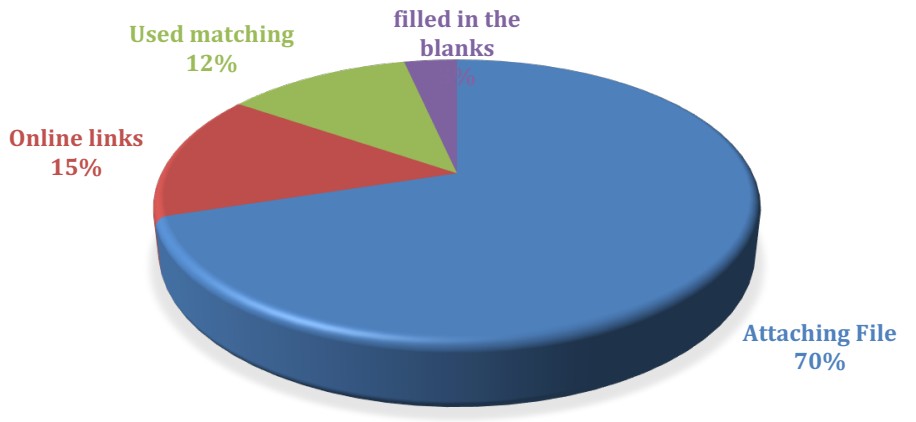

Fig. 5. Proportions of students who accessed the application to complete the exercises

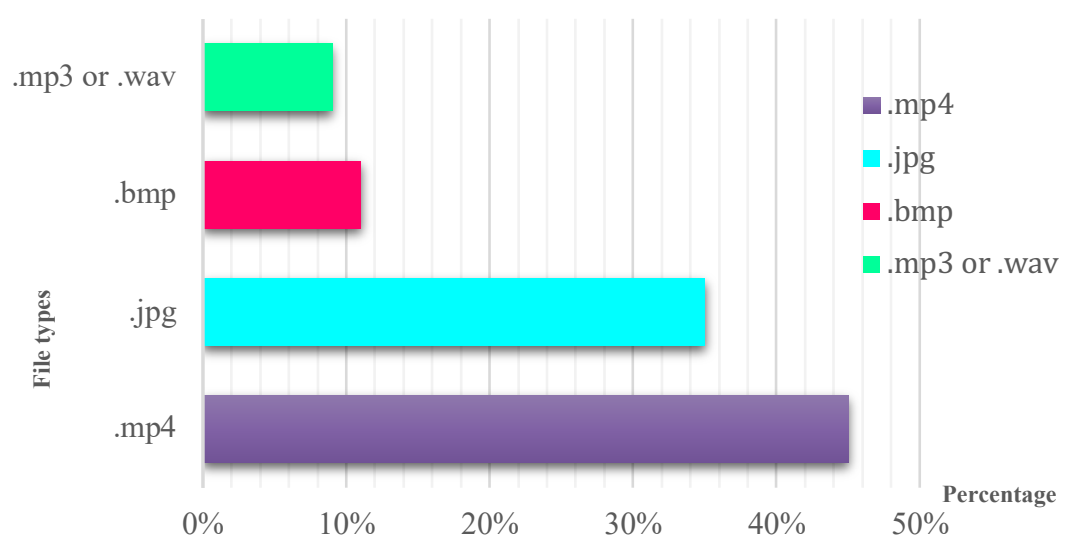

Fig. 6. Proportions of attached riles types used to complete the exercises

\section{Conclusion}

This extended study of undergraduate students' mobile application usage was conducted to propose differentiated (individualized) learning support for lecture-based general education subjects. The content of the mobile application was designed based 
on the gathered information as well as lesson contents and exercises from the textbooks of the eight courses; it was a summary of the contents from each lesson in the form of modern infographics that were suitable for the learners. In addition, the content of the lesson in the form of text that is associated with the PDF files and the Ebooks were linked in mobile application. The exercises included multiple choice and/or fill in the blanks, whilealso permitting the self-creation of content based on each student's personal preferences that may have been determined by their talents, understanding, interests, or topics. The students were also able to submit their answers through the mobile application by attaching files.

Research findings indicate that the number of learners who failed decreased to zero, while learner satisfaction rose with a mean of 4.75 and a standard deviation of 0.43 . In completing the exercises, the most popular means for doing this was via the use of video clip attachments, while the least popular exercises were fill-in-the-blank questions. These results are promising in that it may be suggested that if contemporary education develops with smartphone and mobile application development, learners will be provided with more opportunities to use their creativity, interests, and understanding, to better review the lessons, and enjoy a more engaging atmosphere which greatly stimulates the studying process.

The popularity in completing exercises with file attachments shows that learners were interested in creating their own content according to their own individual preferences. This allows learners to show their skills and knowledge in a creative way, and not being limited by multiple choice or fill-in-the-blank questions, allowing for significant learner satisfaction.

Hence, the developed mobile application is an alternative way to assist learners to be more creative in studying and to better enable the utilization of the smartphones in their education. This also enhances the studying process of the learners, with references to the overall content using infographics and motivating the learners to access lecture materials in PDF form, or even by retrieving resources from the internet by themselves. Additionally, the learners can complete study exercises with a genuine understanding and creativity, by attaching files, and using their smartphones to review the lessons in a timely and convenient manner. This possibly increases the students' ability to learn, which coincides with studies by Shih et al. (2010), Huang et al., (2012), Bomhold (2013), and Kim et al. (2013).

\section{$5 \quad$ References}

[1] D. H. Schunk, "Learning Theories an Educational Perspective, " MA: Pearson Education, Inc., 2012.

[2] B. K. Laura, G. Matthew, L. Stephanie, and M. Sean, "Student Preferences for Small and Large Class Sizes," International Journal of Humanities and Social Science, vol. 5, no. 1, pp. 20-29, 2015.

[3] M. James and S. Robert, "The Impact of Class Size and Number of Students on Out-comes in Higher Education," Robins School of Business University of Richmond, Richmond, V, 2010. 
[4] NOP, "Half of 7-16s Have a Mobile Phone," NOP Research Group Ltd., 2010, http://www.nopres.co.uk/news/news_survey_half_of7-16s.shtml

[5] M. Sharples, "Disruptive devices: mobile technology for conversational learning," International Journal of Continuing Engineering Education and Lifelong Learning, vol. 12, no. 5/6, pp. 504-520, 2003. https://doi.org/10.1504/ijceell.2002.002148

[6] B. Ligi, and D. R. William, "Mobile Learning in Higher Education," International Journal of Research, vol. 5, no. 4, pp. 1-6, 2017.

[7] U. Maria, "Mobile Learning_Trends and Practices," Education Science. vol. 9, no. 33, 13, 2019.

[8] E. Menna, S. Abdulaziz, and E. Hazem, "Mobile Learning System for Egyptian Higher Education Using Agile-Based Approach," Education Research International. pp.1-13, 2019.

[9] H. Crompton, "A historical overview of m-learning: Toward learner-centered education," Handbook of mobile learning, 2013.

[10] P. N. Chandrasena, "ICT in the foreign language classroom in Sri Lanka: A journey through a decade," 10th World Conference on Computers in Education (WCCE 2013), Nicolaus Copernicus University, July 2-5 2013, Torun, Poland, 2013, pp. 223-224.

[11] P. N. Chandrasena, "Introducing Computer Aided Language Learning to Sri Lankan Schools: Challenges and Perspectives," 15th International Conference on Interactive Collaborative Learning and 41st International Conference on Engineering Pedagogy (ICL \& IGIP), Villach, Austria, 2012. https://doi.org/10.1109/icl.2012.6402118

[12] J. Traxler, "Defining, discussing and evaluating mobile learning: The moving finger writes and having writes," The International Review of Research in Open and Distributed Learning vol. 8, no. 2, Article 2, 2007. https://doi.org/10.19173/irrodl.v8i2.346

[13] Z. L. Berge and L.Y. Muilenburg, "Handbook of Mobile Learning," NY: Routledge, 2013.

[14] N. Aharony, "Library and information science students' perceptions of m-learning," Journal of Librarianship and Information Science, vol. 46, no. 1, pp. 48-61, 2014. https://doi.org/10.1177/0961000613518819

[15] T. Cochrane and R. Bateman, "Smartphones give you wings: Pedagogical affordances of mobile Web 2.0," Australasian Journal of Educational Technology. vol. 26, no. 1, pp. 114. 2010. https://doi.org/10.14742/ajet.1098

[16] L. E. Dyson, A. Litchfield, E. Lawrence, R. Raban, and P. Leijdekkers, "Advancing the mlearning research agenda for active, experiential learning: Four case studies," Australa-sian Journal of Educational Technology, vol. 2, no. 2, pp. 250-267, 2009. https://doi.org/10. $\underline{14742 / \text { ajet. } 1153}$

[17] S. Y. Park, "An analysis of the technology acceptance model in understanding university students' behavioral intention to use e-learning," Educational Technology \& Society, vol. 12 , no. 3, pp. 150-162, 2009.

[18] O. Viberg and A. Grönlund, "Cross-cultural analysis of users' attitudes toward the use of mobile devices in second and foreign language learning in higher education: A case from Sweden and China," Computers \& Education, vol 69, pp. 169-180, 2013. https://doi.org/ 10.1016/j.compedu.2013.07.014

[19] N. C. Ken, Y. Noraffandy, H. I. Nor, and S. Johari, (2017). "A Review of Literature in Mobile Learning: A New Paradigm in Teaching and Learning Pedagogy for Now and Then," Advanced Science Letters All rights reserved, vol. 23, pp. 1-6, 2017.

[20] C. Quinn, "M-Learning: Mobile, Wireless, In-Your-Pocket Learning LineZine," 2001, $\mathrm{http}: / /$ www.linezine.com/2.1/features/cqmmwiyp.htm 
[21] J. Keengwe, and M. B. Maxfield, "Advancing Higher Education with Mobile Learning Technologies: Cases, Trends, and Inquiry-Based Methods," Hershey, PA: IGI Global, 2016. https://doi.org/10.4018/978-1-4666-6284-1

[22] P. Lavín-Mera, P. Moreno-Ger, and B. Fernández-Manjón, "Development of educa-tional videogames in m-Learning contexts," Digital Games and Intelligent Toys Based Education. pp. 44-51, 2008. https://doi.org/10.1109/digitel.2008.21

[23] A. Kukulska-Hulme, and J. Traxler, "Mobile learning: a handbook for educators and trainers," New York: Routledge Falmer, 2005. http://doi.org/10.1111/j.1467- 8527.2009.437 $\underline{6 . x}$

[24] J. G. Caudill, "The growth of m-learning and the growth of mobile computing: Parallel developments," The International Review of Research in Open and Distributed Learning, vol. 8, no. 2, 2007.

[25] S. Hussin, M. R Manap, Z. Amir, and P. Krish, "Mobile learning readiness among Malaysian students at higher learning institutes," Asian Social Science, vol. 8, no. 12, pp. 276283, 2012. https://doi.org/10.5539/ass.v8n12p276

[26] T. Franklin, "Mobile learning: At the tipping point," The Turkish Online Journal of Educational Technology, vol. 10, no. 4, 2011.

[27] J. O'Donoghue, "Technology-Supported Environments for Personalized Learning: Methods and Case Studies," Hershe. PA: IGI Global, 2010.

[28] M. Prensky, "Digital natives, digital immigrants' part 1,". The Horizon, vol. 9, no. 5, pp. $1-6,2001$.

[29] C. R. Bomhold, "Educational use of smart phone technology: A survey of mobile phone application use by undergraduate university student," Program: Electronic Library and Information Systems, vol. 47, no. 4, pp. 424-436, 2013. https://doi.org/10.1108/prog-012013-0003

[30] J. Kim, L. Ilon, and J. Altmann, "Adapting smartphones as learning technology in a Korean university," Journal of Integrated Design \& Process Scienc, vol. 17, no. 1, pp. 5-16, 2013.

[31] R. T. Huang, S. J. Jang, K. Machtmes, and D. Deggs, "Investigating the roles of per-ceived playfulness, resistance to change and self-management of learning in mobile Eng-lish learning outcome," British Journal of Educational Technology, vol. 43, no. 6, pp. 10041015, 2012. https://doi.org/10.1111/j.1467-8535.2011.01239.x

[32] J.-L Shih, C. W. Chuang, and G. J. Hwang, "An Inquiry-based Mobile Learning Ap-proach to Enhancing Social Science Learning Effectiveness," Educational Technology \& Society, vol. 13 , no. 4 , pp. 50-62, 2010.

[33] M. R. Lynn, "Determination and quantification of content validity," Nursing Research, vol. 35 , pp. 382-385, 1986.

[34] E. A. Lee, K. W Wong, and C. C. Fung, "How does desktop virtual reality enhance learning outcomes? A structural equation modeling approach," Computers \& Education, vol. 55, pp. 1424-1442, 2010. https://doi.org/10.1016/j.compedu.2010.06.006

[35] F. D. Davis, "Perceived Usefulness, Perceived Ease of Use, and User Acceptance of Information Technolog," MIS Quarterly, vol. 13, pp. 319-34, 1989. https://doi.org/10.2307/ $\underline{249008}$

[36] E. McAuley, T. Duncan, and V. V. Tammen, "Psychometric properties of the Intrinsic Motivation Inventory in a competitive sport setting: a confirmatory factor analysis," Research Quarterly for Exercise and Sport. vol. 60, pp. 48-58, 1989. https://doi.org/10.1080/027013 $\underline{67.1989 .10607413}$ 
[37] A. Antonietti, E. Imperio, C. Rasi, and M. Sacco, "Virtual reality and hypermedia in learning to use a turning lath," Journal of Computer Assisted Learning, vol. 17, pp. 142-155, 2001. https://doi.org/10.1046/j.0266-4909.2001.00167.x

[38] S. W. Chou and C. H. Liu, "Learning effectiveness in a web-based virtual learning environment: A learner control perspective," Journal of Computer Assisted Learning. vol. 21, pp. 65-76, 2005. https://doi.org/10.1111/j.1365-2729.2005.00114.x

\section{Acknowledgement}

I would like to express our gratitude to the Institute for Research and Developoment, Suan Sunandha Rajabhat University, who offered us the opportunities to conduct this research

\section{$7 \quad$ Author}

Sumitra Nuanmeesri received the Ph.D. degree in information technology from King Mongkut's University of Technology North Bangkok. She is Assistant Professor with the Department of Information Technology, Faculty of Science and Technology at Suan Sunandha Rajabhat University, Bangkok 10130 Thailand. Her research interests include deep learning, computer vision, image processing, mobile application, augmented reality and virtual reality.

Article submitted 2019-03-25. Resubmitted 2019-06-25. Final acceptance 2019-06-25. Final version published as submitted by the authors. 